\title{
A ANÁLISE DE DISCURSO É POSSÍVEL?
}

\author{
Eni Puccinelli Orlandi \\ LABEURB/UNICAMP
}

Resumo: Na história das ideias discursivas, importa, nesse textohomenagem à M. Pêcheux, lembrar a sua questão fundadora que se estampa no título desta reflexão e os muitos movimentos de busca, compreensão, explicitação, retomadas e deslocamentos, produzidos por este autor. O início de suas reflexões pode ser posto em muitos de seus textos dispersos, mas costuma-se tomar este seu livro, AAD69resultado de sua tese - como o patamar fundador da Análise de Discurso, que ele propõe. Aqui fazemos, pois, uma exposição do que consideramos como marcos importantes de sua reflexão e de constituição desta ciência.

Résumée: Dans l'histoire des idées discursives, il est important dans ce texte qui rend hommage à $M$. Pêcheux de rappeler sa question fondatrice, qui est gravée dans le titre de cette réflexion, ainsi que les nombreux mouvements de recherche, de compréhension, d'explicitation, de reprise et de déplacement produits par cet auteur. Le début de ses réflexions peut être mis dans beaucoup de ses textes épars, mais son livre, AAD69 - le résultat de sa thèse - est souvent considéré comme la marque fondatrice de l'Analyse du Discours qu'il propose. Nous présentons ici un exposé de ce que nous considérons comme des jalons importants de sa réflexion et dans la constitution de cette science.

Em Creta onde o Minotauro reina atravessei a vaga De olhos abertos inteiramente acordada

Sem drogas e sem filtro

Só vinho bebido em frente da solenidade das coisas Porque pertenço à raça daqueles que percorrem o labirinto, Sem jamais perderem o fio de linho da palavra (c) ) EY-NC-SA

Líng. e Instrum. Linguíst., Campinas, SP, n. 44, p. 138-156, jul./dez. 2019 
(Sophia de Mello Breyner Andersen, Dual)

\section{Uma pergunta e seus efeitos}

Não poderia iniciar este texto, que homenageia os 50 anos do livro Analyse Automatique du Discours (AAD69), de M. Pêcheux (1969), sem referir a sua questão fundadora: A Análise de Discurso é possível? Esta era a questão que M. Pêcheux se colocava, com insistência, e a vários de seus interlocutores, nos anos 70 do século XX. Questão que ficou como um eco a nos desafiar, menos no desenvolvimento da Análise de Discurso, e mais na possibilidade de elaborações e avanços teóricos que não esbarrassem em uma proposta fechada e inerte. Porque ela produz rupturas, desacostuma, ela subverte já-ditos, ela não fecha questão, preferencialmente as abre. Já que, como diz seu criador, M. Pêcheux: "Não são as respostas que envelhecem, são as questões".

A pergunta que deixamos como título, e que rondava a publicação de seu livro Analyse Automatique du Discours ${ }^{1}$, esta pergunta, era, antes de tudo, a que estabelecia, para o próprio autor, a noção de discurso, e se dirigia, sobretudo mais diretamente, aos linguistas de quem ele se aproximara ${ }^{2}$. Porque, na conjuntura dos anos 60/70 do século XX, a interrogação posta nesta questão era a da formalização da Análise de Discurso, ou seja, ele se perguntava como "dar conta" de um objeto das Ciências Humanas. Como estabelecer uma "escrita" para a análise, um artefato analítico, com seu método? Pergunta sobre a modelização, recorrente neste momento do desenvolvimento das Ciências, e das relações das Ciências Humanas e Sociais com os modelos validados, com sua universalidade, legítimos, como os das Ciências Exatas e Naturais ${ }^{3}$.

\section{Modelização e Ciências da Linguagem}

Toda ciência tem sua escrita. A da linguagem tem a sua. E a proposta de uma escrita para as ciências da linguagem, no século XIX, inaugura um seu lugar diferenciado entre as ciências humanas e sociais, o dos estudos histórico-comparados da linguagem $(\mathrm{pl} \rightarrow \mathrm{ch} /$ pluviam $>$ chuvia $>$ chuiva $>$ chuva). Mas a escrita do século XIX, para os estudos da linguagem, não é suficiente, no século XX. Esta escrita não é a mesma nas diferentes conjunturas científicas, dos estudos da linguagem, que validam modelos e lhes dão legitimidade. 


\section{e instrumentos \\ LINGÜÍSTICOS}

Segundo sua definição, no nível epistemológico do que se discute desde o século XX, para a linguagem, a modelização exige mais, ela consiste, essencialmente, na arte de transformar situações da realidade em problemas matemáticos cujas soluções devem ser interpretadas na linguagem usual (BASSANEZI, 2002, p.24). Tanto que um dos investimentos fortes dos estudos da linguagem foi, inicialmente, o de aplicar o modelo dos quadros formais da matemática à linguagem. Além daquele que propõe a informatização, como é o caso desta proposta da AAD69.

A forma dominante de modelização nos anos 60/70 do século XX, questão insistente da época, como dissemos, se declinava como formalização. Lembremos que esta busca era a de tornar formal algo considerado "subjetivo"4; tornar, então, palpável, visível, perceptível, através de papeis, documentos e outros procedimentos formais. Quando posta em relação à Linguística, a resposta já estava circulando, e era favorável ao mérito, à legitimidade dessa ciência da linguagem: a Linguística era o modelo, no campo das Ciências Humanas, de uma ciência bem sucedida em sua formalização (cf. a Gramática Gerativa e as regras de reescrita e seus indicadores sintagmáticos) ${ }^{5}$. Tanto, que era reconhecida como ciência-piloto das Ciências Humanas. Já quando se tratava deste objeto obscuro de desejo do cientista, o discurso, em que entravam sujeito e situação, a pergunta ficava indecisa, tinha suas oscilações. Seria possível? A informatização ${ }^{6}$ foi uma iniciativa de resposta forte de M. Pêcheux, nesta direção ${ }^{7}$.

Esta possibilidade se vincula, nesta perspectiva a que estamos referindo - que é a da legitimidade do conhecimento, e sua validação por um padrão, que aspira à universalidade -, à normatividade da escrita da ciência, padronizada na lógica e na matemática ${ }^{8}$. Sem esquecer que os algoritmos e a presença das tecnologias da informação já eram uma realidade incontornável.

Para se formalizar, a Linguística se produziu uma escrita, mas, para isso, teve de "esquecer" o sujeito e a situação. Esquecimento voluntário. Já por seu lado, a Análise de Discurso, para se constituir, tem de trazê-los para sua consideração. Não o sujeito e a situação, como tal, ou seja, como formulados pelas teorias da época (penso fundamentalmente nos funcionalismos e na pragmática), mas o sujeito decentrado e a situação, concebida, não em si, mas metaforizada pela 


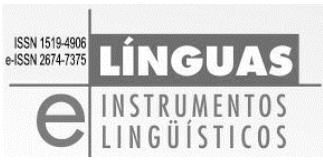

articulação entre o simbólico e o político. Projeção da situação, no discurso, através das formações imaginárias. Relação da linguagem com sua exterioridade. O que resulta na conceituação do que vem a se denominar "condições de produção", e em seus desenvolvimentos, no texto da AAD69. Implicando a relação linguagem e ideologia.

Esta é a natureza da situação, ou melhor, da "exterioridade" que se configura, se conforma, toma lugar teórico, segundo os princípios da Análise de Discurso. Daí a afirmação de M. Pêcheux, fazendo intervir a noção de funcionamento, criticando a noção de função:

(...) enunciaremos, a título de proposição geral, que os fenômenos linguísticos de dimensão superior à frase podem efetivamente ser concebidos como um funcionamento, mas com a condição de acrescentar, imediatamente, que este funcionamento não é integralmente linguístico, no sentido atual do termo, e que não se pode defini-lo senão em referência ao mecanismo da colocação dos protagonistas e do objeto do discurso, mecanismo que chamamos "as condições de produção” do discurso (PÊCHEUX, 2019 [1969], p. 35).

No mesmo gesto teórico, M. Pêcheux (2019 [1969], p. 35), fala do não fechamento do texto, na sua relação com os discursos possíveis:

(...) Isto supõe que é impossível analisar um discurso como um texto, isto é, como uma sequência linguística fechada sobre si mesma, mas é necessário referi-la ao conjunto de discursos possíveis a partir de um estado definido das condições de produção, como mostraremos em seguida ${ }^{9}$.

Poder-se-ia interrogar: o que torna a Análise de Discurso possível é a "sobra" para a qual a Linguística não tem procedimento nem resposta? Sobra esta que põe em estado de questão não só a Linguística como as Ciências Humanas e Sociais, e estabelece o espaço teórico para o que virá a ser a Semântica Discursiva? A resposta não é tão fácil assim.

\section{Uma relação e um distanciamento}




\section{e instrumentos \\ LINGÜÍsticos}

M. Pêcheux (1988 [1975]) distingue a Semântica Linguística e a Semântica Discursiva. A Semântica Linguística é uma semântica formal que, segundo ele, ainda não estava feita ${ }^{10}$. Seria "uma teoria do funcionamento material da língua na sua relação com ela mesma, isto é, uma sistematicidade que não se opõe ao não sistemático (língua/fala), mas que se articula sobre processos" (PÊCHEUX, 1988 [1975], p. 173). Já a Semântica Discursiva “é a análise científica dos processos característicos de uma formação discursiva, que deve dar conta da articulação entre o processo de produção de um discurso $e$ as condições $^{11}$ em que ele é produzido. Não é uma semântica lexical, e deve ter como objeto os processos de arranjo dos termos em uma sequência discursiva e em função das condições em que a sequência discursiva é produzida" [grifo meu] (PÊCHEUX, 1988 [1975], p. 174) ${ }^{12}$.

Dois pontos, eu diria, nesta definição de Semântica Discursiva, nos colocam em estado de interrogação: a. arranjo dos termos em uma sequência discursiva; b. em função das condições em que a sequência discursiva é produzida. Em a. temos de saber observar/descrever o "arranjo dos termos"; temos, além disso, de saber o que é uma "sequência discursiva". Ele diz sequência discursiva (não diz enunciado, embora, em sua análise ele fale em enunciado), o que, certamente, nos indica que não é uma sequência linguística. Em b. intriga-nos como entender "em função das" condições em que a sequência discursiva é produzida. O que significa aí "em função de"? É a noção de determinação que aí se aloja? E, nesta sua formulação, está a distinção da Semântica Discursiva em relação à Semântica Linguística, que coloca a perspectiva da modelização. Uma, a linguística, já se mostra, embora ainda não feita, passível de um tratamento formal, portanto, modelizável. E a outra, a discursiva, que inclui as condições de produção? Ela é possível? ${ }^{13}$ Certamente o é, mas não como a semântica linguística.

Um dos elementos, que faz a distinção, diz respeito à questão do efeito-sujeito. Segundo Pêcheux, com esta distinção, entre semântica formal e semântica discursiva, é possível atingir o lugar específico da língua que corresponde à construção deste efeito. Desse modo, a análise não reproduziria o efeito-sujeito e, ao mesmo tempo, reconheceria sua existência. O linguístico e o discursivo permanecem distintos, heterogêneos, mas não há entre eles uma distinção estanque. 
Como afirma Pêcheux (1988 [1975]), as sistematicidades da língua não existem sob a forma de um bloco homogêneo de regras organizadas à maneira de uma máquina lógica. As fronteiras entre língua e discurso são sempre colocadas em causa, pois é próprio desta relação que as regras fonológicas, morfológicas e sintáticas ${ }^{14}$, que são as condições materiais de base sobre as quais se desenvolvem os processos discursivos, sejam objeto de recobrimentos e de apagamentos parciais. Por outro lado, não esqueçamos que, para Pêcheux (1988 [1975], p. 258): “a exterioridade do pensamento não está ligada a puras propriedades linguísticas, mas dependem de um "exterior" bem diferente que é o conjunto dos efeitos, na esfera da ideologia, da luta de classes sob suas diversas formas" [grifo meu]. Daí resulta a proposta da análise de discurso, que demanda uma teoria não subjetiva da enunciação, e que exige que se considere o texto não como um nível superior de análise, mas que se observe a relação das condições materiais de base e o processo, trabalhando com a noção de funcionamento e de ideologia (efeitos, formações imaginárias). Como mudam as condições de produção e a ideologia dos sujeitos, mantémse a base comum para não nos encontrarmos frente a um pluralismo heterogêneo de microlínguas.

Retomo aqui a busca, deste autor, de um modelo ao gosto da época em sua validação científica e à proposta da análise automática do discurso feita por ele. Busca que passa pela informatização, como escrita própria. Que lhe dá um instrumento para pensar a análise, tomando como unidade o enunciado, procurando abranger a relação da linguagem com suas condições de produção (sujeito e situação; e eu acrescento: memória). Podemos dizer que este modelo não teve o sucesso esperado/desejado ${ }^{15}$, mas é heurísticamente muito produtivo. $\mathrm{O}$ que se pode depreender pelos desenvolvimentos posteriores a esse seu livro AAD/69, sobretudo no Les Vérités de La Palice (1975) e em seu artigo, com C. Fuchs, na revista Langages 37 (também de 1975, 1975a). Mas, se, com a informatização, ele não ganha ainda a legitimação de seu modelo e de uma sua escrita formal, no entanto, seu interesse pela informatização, em uma conjuntura em que se pensa a tradução automática, modelos matemáticos para a linguagem, e em que as tecnologias de informação começam seu enorme desenvolvimento, o coloca como um precursor. Esta sua posição se constitui não só pela natureza das questões que suscita, mas também 
pela qualidade das respostas que busca. Não se trata, portanto, de pensar os conteúdos daquilo que vai se construindo com seus "andaimes", mas de seus procedimentos na busca das noções que vão constituindo seu caminho e as possibilidades de analisar discursos. Ele está, ao mesmo tempo, produzindo uma teoria e estabelecendo procedimentos de análise na construção de um método.

Resta, neste sentido, falar da maneira que o autor discute a relação língua/fala. Podemos aí inserir suas questões sobre a busca dos sentidos do texto, em várias disciplinas, que o leva à crítica dos modelos que ele chama de infra-linguísticos ou supra-linguísticos, assim como daqueles que não superam dificuldades para passar da função ao funcionamento. Ainda a este respeito, frente ao que o autor (idem) chama de métodos para-linguísticos, há já um desenvolvimento em relação a esta questão, quando M. Pêcheux parte de uma afirmação de Levi-Strauss (1964, p.13) - "Como os ritos, os mitos são intermináveis....Assim o livro sobre os mitos é ele próprio um mito" que o leva a considerações importantes, para a análise de discurso nascente (e sua possibilidade), a respeito de seu objeto, e ao funcionamento da língua. De início, mostrando que não há homogeneidade epistemológica entre fatos da língua e os fenômenos da dimensão do texto. Não se pode transportar os mesmos instrumentos conceptuais de um para outro. O exemplo que ele dá é o da relação paradigma/sintagma e sua forte presença na linguística, que não pode ser meramente transposta, pois há resistência do objeto. A disjunção entre a teoria da língua e a prática do locutor, para a linguística, foi adquirida, alcançando-se o funcionamento da língua, separando-a da prática do locutor.

Mas não é o caso quando se trata do discurso. Nesse caso, se fosse se "aplicar" os mesmos instrumentos resultaria em que o funcionamento do texto avizinha ainda sua função e o deslocamento necessário para o analista de discurso não se daria. Ou seja, não é possível transpor para a análise de discurso um instrumento descritivo como o da relação paradigma/sintagma. Mas sabemos que, com a noção de efeitos metafóricos (AAD69), e a noção de deriva, $\mathrm{M}$. Pêcheux (1990) estabelece procedimentos e instrumentos próprios ${ }^{16}$ à análise discursiva, para tratar de uma questão fundamental, a de deslizamento de sentido, elaborando o desenvolvimento da relação entre estrutura/acontecimento que leva ao batimento, como diz 


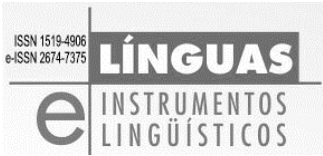

Pêcheux, entre descrição/interpretação. E à articulação entre paráfrase (repetição) e metáfora (transferência), entre o estabilizado e o sujeito à equívoco. Com a noção de efeitos metafóricos, temos um instrumento de análise com suas consequências. E temos, paralelamente, um corte na continuidade entre teoria e prática, no caso, discursiva. Trata-se, como Pêcheux diz (AAD69), de um problema que concerne "o acesso ao objeto",17.

\section{Na ruptura epistemológica a conquista de outra região de conhecimento}

Em relação à linguística trata-se da mudança de terreno que o autor propõe já em seu AAD69 quanto à relação língua/fala. Para tal, ele explora o que diz Ulmann (1952) sobre a antinomia, na Linguística, entre língua e fala. A fala é um ato, diz Ulmann (idem), que pressupõe um contexto, uma situação concreta e determinada, enquanto a língua é "um sistema virtual que só se atualiza na e pela fala". Sendo a fala um "ato individual", ele se opõe "ao caráter social" da língua. Com suas reflexões, Pêcheux, vai mostrar que esta forma de considerar a relação língua/fala faz com que a operação de exclusão da fala, feita por Saussure, mesmo que ele não tenha querido explicitamente, autoriza o "reaparecimento triunfal do sujeito falante como subjetividade em ato, uma unidade ativa de intenções que se realizam pelos meios postos à sua disposição". Se passa, assim, da necessidade do sistema à contingência da liberdade. Nada mais estranho à análise de discurso que este sujeito e esta língua, e esta noção de fala assim concebidas.

Em suas "questões conceptuais para uma teoria do discurso", $\mathrm{M}$. Pêcheux (AAD69), entre suas muitas elaborações, afirma - já de início, na mudança de terreno estabelecida epistemologicamente - que o estudo dos processos discursivos supõe o estudo das variações específicas ligadas aos processos de produção particulares considerados, e o estudo da ligação entre as "circunstâncias" de um discurso - que ele propõe chamar de condições de produção - e seu processo de produção. Este, por sua vez, designa o conjunto de mecanismos formais que produzem um discurso de um tipo dado em "circunstâncias" dadas. Ora, é aí que se pode situar a disjunção entre teoria e prática, e a relação não entre língua e fala, mas língua e discurso, este definido como efeito de sentidos entre locutores. Que 
não são tomados como subjetividades, mas considerados como parte das condições de produção do discurso: não indicam "organismos humanos individuais" (PÊCHEUX, 2019 [1969], p.39), mas lugares determinados em uma estrutura social determinada, com a diferença, em relação à sociologia, que não são representados como feixes de traços objetivos nos processos discursivos, mas estão presentes mas transformados; o que funciona no discurso, diz o autor, é uma série de formações imaginárias. Em outras palavras, já está aí presente não a subjetividade em ato, mas a interpelação ideológica do indivíduo em sujeito, e a constituição da posição-sujeito. Assim ele ultrapassa o que era a fala como ato individual oposta à língua, que teria caráter social, em Saussure; não ficando, pois, na estrita oposição indivíduo e sociedade. Pensando a ideologia como constitutiva do sujeito e dos sentidos, esta oposição (indivíduo e sociedade) não é vigente na teoria do discurso ${ }^{18}$. São estas algumas "mudanças" teóricas que achamos oportuno lembrar deste imenso programa intelectual que se inicia com o livro AAD69 de M. Pêcheux.

\section{Funcionamento, exterioridade e processo discursivo: as formações discursivas e a ideologia}

$\mathrm{Na}$ realidade, este é só o início de um projeto forte que se faz impulsionado por um intelectual de vasta formação em Filosofia e que está atento às Ciências Humanas, à questão da Ideologia e dos Sujeitos, na sociedade e na história. Pensando, sobretudo, a conjuntura político-intelectual dos anos de 1960, e olhando para a Linguística (língua) como um de seus campos metafóricos de debate. Os outros campos, como sabemos, são a Psicanálise (inconsciente) e o Marxismo (história).

É na relação contraditória entre estes campos que insistimos com nosso olhar para melhor abranger a crítica ao modo de se considerar a modelização que a própria forma da análise de discurso se desenvolver mostra. Nessa direção, uma das questões, postas para o encontro de que resultou o livro Materialidades Discursivas (2016 [1981]), nos toca mais de perto: “de que natureza é a decepção diante das disciplinas que pretendem falar da língua, do texto, do discurso, da fala...?". Ou outra das interrogações, sobre a qual já me debrucei, mas permanece desafiando minha reflexão: "De que nos protegemos ao nos declararmos linguistas, historiadores ou psicanalistas?”. O que não 
é isto, nem cabe aí, me pergunto, quando tratamos do discurso? Do que estamos desprotegidos, nós, analistas de discurso, já que não nos situamos em nenhuma das possibilidades acima postas? Seria da modelização, o que nos afastaria da legitimidade da ciência? Da modelização, tal como concebida na época, talvez, mas, certamente, o projeto de tornar a Análise de Discurso possível, não nos afasta da legitimidade da ciência. Essa, adquirida, só que em outros modelos com outras interrogações. Trata-se de um corte epistemológico nos estudos e pesquisas da linguagem.

Para isto vamos tomar a noção de condições de produção, que está na base da formulação da especificidade e da possibilidade mesma da análise de discurso, e que é um conceito fundamental em seu discurso fundador da análise de discurso, em sua obra AAD69. O que mostra a necessidade de se manter uma relação consistente entre teoria, método e análise de um objeto de ciência em sua definição.

Esta noção, que é, como dissemos, uma noção fundadora, presente no AAD69, desenvolve-se arrebanhando sentidos de "exterioridade", "interdiscurso", "processo discursivo", "domínio semântico e circunstâncias", produzindo, ao mesmo tempo, um suporte metodológico. Nesta direção, da constituição de um método, por exemplo, trazemos a afirmação de que "em uma situação de análise temos condições que remetem, a um mesmo domínio semântico, diferentes discursos", em "circunstâncias" dadas (PÊCHEUX, 2019 [1969], p.74). Também a definição, neste passo de sua reflexão, do que é "processo de produção do discurso" que, como a noção de "condições de produção", vai sendo retomada e significada incessantemente em relação ao conjunto de noções em que está inserida. $\mathrm{O}$ "processo de produção: conjunto de mecanismos formais que produzem um discurso de tipo dado em circunstâncias dadas" (PÊCHEUX, 2019 [1969], p. 31). Já no Vérités de La Palice, o processo aparece da seguinte maneira, agora, já significado, dito, como "processo discursivo": "(...) a expressão processo discursivo passará a designar o sistema de relações de substituição, paráfrases, sinonímias, etc, que funcionam entre elementos linguísticos "significantes" - em uma formação discursiva dada" (PÊCHEUX, 1988 [1975], p.161). Penso que aí se pode flagrar um desenvolvimento da reflexão, em que ele já está mais posto na possibilidade da análise - menos preocupado com a modelização, 
pois, de certo modo, já a realizando - não precisa pensar só a língua (mecanismos formais) e o discurso (tipo de discurso de acordo com as circunstâncias), mas já o processo discursivo (paráfrase, metáfora, substituição, formação discursiva). Algo aí já se articulou. Isto, a meu ver, se deve às noções de formação discursiva ${ }^{19}$, já se constituindo na AAD69, junto à noção de interdiscurso, já bem estabelecidas, em seguida, no Vérités. O importante, a meu ver, quanto à modelização, é a formulação de noções que permitem pensar desde o início - AAD69 - a relação do discurso com o seu fora. A relação da língua com a ideologia. Do ponto de vista da prática analítica, dos procedimentos, a relação entre noções como "condições de produção" e "processo de produção" do discurso - este último já definido como "estado do processo discursivo" - é um início fundante rigoroso e extremamente produtivo para as reflexões que o autor provoca e que serão desenvolvidas em muitas retomadas e em vários outros textos. Como a noção de formação discursiva como projeção, no discurso, de formações ideológicas. Dessa forma, tratando da relação ideologialinguagem, ele produz um deslocamento fundamental que é o de considerar a ideologia não como "sintoma", mas como parte da materialidade mesma da linguagem. A ideologia como constitutiva do discurso, sua materialidade específica. Pêcheux articula, ao mesmo tempo, pela noção de interpelação ideológica, linguagem e ideologia, sujeito e sentidos, no que ele propõe como formação discursiva. Liga a esta, a produção dos sentidos, e a identificação dos sujeitos. A formação discursiva, cujo tratamento vai sofrendo ressignificações como a ideia de suas fronteiras fluidas ou da heterogeneidade que constitui a relação entre elas - torna-se um fundamento analíticometodológico fundamental, na medida em que se trabalha não só a simbolização do político, mas também a movência dos sentidos, dos sujeitos, e a noção de equívoco.

Por seu lado, a definição de "processo discursivo" traz nela as muitas possibilidades de procedimentos na análise, como referimos mais acima. Uma questão de método: sistema de relações, substituição, paráfrases, sinonímia, que remetem aos "efeitos metafóricos", já presentes no AAD69 (PÊCHEUX, 2019 [1969], p. 54-61). E estes à noção de deriva (PÊCHEUX, 1990, p.53), ligada ao fato de que não há metalinguagem e à afirmação de que toda descrição está exposta ao equívoco: "todo enunciado é intrinsecamente 


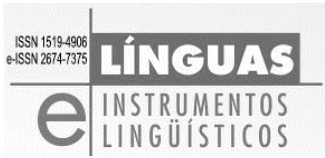

suscetível de tornar-se outro, diferente de si mesmo, se deslocar de seu sentido para derivar para outro", a não ser que haja "proibição explícita de interpretação". Esta, própria ao "logicamente estável". A possibilidade de deriva, de deslizamentos, já está anunciada no AAD69, quando o autor refere que "toda forma discursiva particular remete necessariamente à série de suas formas possíveis, e que estas remissões da superfície de cada discurso às superfícies possíveis (...) constituem precisamente os sintomas pertinentes do processo de produção dominante regendo o discurso submetido à análise" (PÊCHEUX, 2019 [1969], p. 63). Esta afirmação, pensamos, pode remeter, considerando-se os efeitos metafóricos (AAD69), à concepção de "famílias parafrásticas" que se formam ao longo dos enunciados, noção bastante desenvolvida em seu texto com C. Fuchs (1975a), e que é um instrumento de análise muito produtivo. Desse modo, queremos apontar para muitas das elaborações do autor em seu AAD69, enquanto noções, propostas nascentes, que se desenvolvem, depois, continuamente, em seus outros textos, constituindo uma consistente relação entre teoria-método-objeto.

\section{Apontamentos sobre a produção da Análise de Discurso brasileira, a partir do AAD69}

A questão da modelização foi uma questão que se apresentou para todos os pesquisadores de linguagem que se filiavam à Análise de Discurso $^{20}$, em qualquer parte do mundo: um objeto novo que requeria, para sua análise, procedimentos específicos e particulares às noções que se desenvolviam então.

É neste ponto que gostaria de me manifestar, em minha formação de linguista, que me permitiu, em meus inícios, encontrar os lugares teóricos, na leitura de M. Pêcheux (1969), por onde proceder a uma análise que nem era automática e nem se curvava ao formalismo linguístico. Em minhas análises, sempre atenta à teoria, trabalhava na explicitação/constituição de um método. E isto se deu, já no início, pela tensão entre paráfrase e polissemia ${ }^{21}$ (ORLANDI, 1983) que propus como eixo do funcionamento da linguagem. Aí eu significava a relação entre o mesmo (reprodução, repetição) e o diferente (substituição, diferença). E, ainda sem conhecer o texto "Discurso: estrutura ou acontecimento?", texto apresentado em Congresso, por Pêcheux, em 1983, em inglês (Urbana, USA), e em tradução brasileira 
em 1990, minhas análises, desde os anos 70 do século XX, trabalhavam essas relações em geral, e, em particular, as de substituição, que produzem aproximação e diferença. Isto me chegou também pela leitura atenta (PÊCHEUX, 2019 [1969], p.35) de que, como já citamos anteriormente, "é impossível analisar um discurso como um texto ${ }^{22}$, isto é, como uma sequência linguística fechada sobre ela mesma, mas é preciso referi-la ao conjunto de discursos possíveis a partir de um estado definido das condições de produção". Além, claro, de levar em conta as posições-sujeito - constituídas pela projeção, através de formações imaginárias, da situação, do lugar do sujeito, no discurso - observando sempre as relações de força, as de sentido e a antecipação, já propostas desde o AAD69. A consideração da noção de processo e de estado do processo discursivo, assim como a relação, em um texto, do que ali se apresenta frente aos muitos discursos possíveis - que são alguns entre muitos outros princípios que vão se alinhando ao longo de sua escrita - foram propícios à formulação que dei à noção de versões (ORLANDI, 2001).

Com estes instrumentos e sua proposta teórica com seus princípios, este texto fundador de Pêcheux, a AAD69, já possibilitava - a mim, pelo menos ${ }^{23}$ - a aventura da busca de possibilidades analíticas ${ }^{24}$, sem temer o fantasma da modelização ${ }^{25}$. Em minha formação, a sintaxe, ou melhor, o real da língua, em sua ordem, eu já havia intuído nas minhas aulas de latim, onde aprendi em profundidade o que é "estrutura"26. Fui estruturalista, o que foi importante em minha formação de linguista, mas, para fazer Análise de Discurso, tive de questionar o método, e realizar análises, que demandavam outra iniciativa, que Pêcheux propõe com a articulação da estrutura com o "acontecimento" (PÊCHEUX, 1990). Esta articulação permite à Análise de Discurso, como diz Pêcheux, questionar teoricamente "o estatuto das discursividades que trabalham um acontecimento, entrecruzando proposições de aparência logicamente estáveis (...) e formulações irremediavelmente equívocas" (1990, p.28). A relação entre processo de produção e condições de produção do discurso (AAD69), abria para esta possibilidade de análise que leva em conta o movimento e a não estabilidade, tão bem posta por Pêcheux (1990) em seu Discurso: estrutura ou acontecimento.

Podemos, enfim, dizer que o livro AAD69 é extremamente sensível, em suas interrogações, ao que é situação, ao que é sujeito, ao 
que é discurso; assim como interroga como se pode apreender a ideologia, através de noções como a de exterioridade (condições de produção) e também a de formação discursiva; propondo-se, como dissemos, produzir uma análise, deslizando da noção de função para a de funcionamento, atento à relação sujeito, sentido, ideologia, e à noção de processo. São fundamentos, princípios teóricos e analíticos, que estão já postos no AAD69 e que lhe dão o mérito de ser um livro fundador, em que se reconhece o lugar de corte epistemológico que o autor produz nos estudos da linguagem e também no da ideologia. Quanto à ideologia, podemos afirmar que esta sua obra produz um grande deslocamento, frente as Ciências Humanas e Sociais, ao considerar a ideologia através da sua relação com a linguagem, e, através desta, o autor produz forte crítica à análise de conteúdo, que era o instrumento comum da análise de linguagem nesse campo. Assim, Pêcheux atinge também um ponto fundamental que constitui as Ciências Humanas e Sociais desde o século XIX.

\section{A interrogação que abriu espaço para constituir um novo objeto de ciência.}

São estes, penso, os caminhos que Pêcheux abre para instituir o modelo que, se, em seu livro AAD69, apresenta-se com a informatização, abre, também, ao mesmo tempo, perspectivas que, confrontando-se com as diferentes conjunturas epistemológicas, continuam, vivamente, interrogando a relação entre a linguagem e a exterioridade, em outras palavras, o sujeito, a articulação entre o simbólico e o político, e a ideologia, na constituição dos sentidos. O que permite que se encontrem muitos caminhos para responder à modelização e a sua questão: a Análise de Discurso é possível?

Se foi esta a questão que se impôs a Pêcheux, logo em suas primeiras formulações, pensando a questão de teoria/método, foi também no que ela implicava para este autor fundador, em sua própria trajetória, que essa interrogação se constitui na formulação de base da teoria que ele aí funda com sua proposta de nos fazer compreender o que existe, afinal, entre a linguagem e a ideologia, implicando os sujeitos e os processos de significação. Esta, pois, a questão que realmente traça o sulco de uma reflexão que não se submete às teorizações de sua época, embora se relacione a elas. E é na sua dúvida, no não fechamento de uma resposta, que sua teoria constrói as 
possibilidades de um programa de reflexões que resulta na constituição de uma teoria, de um método e um novo objeto teórico: o discurso. Que nos faz navegar continuamente entre o possível e o impossível, em busca do real.

\section{Referências Bibliográficas}

BASSANEZZI, R. C. (2002). Ensino-aprendizagem com modelagem matemática: uma nova estratégia. São Paulo: Editora Contexto.

FELIPPO, A. Di, DIAS-DA-SILVA, B. C. (2009). “O processamento automático de línguas naturais enquanto engenharia do conhecimento linguístico”. In: Caleidoscópio, v.7, n.3, p.183-191. São Leopoldo: Unisinos.

FUCHS, C. e PÊCHEUX, M. (1975a). “A propósito da análise automática do discurso: atualização e perspectivas". In: Langages, Paris: Larousse.

HENRY, P. (1993). "Sentido, sujeito, origem". Trad. Eni Puccinelli Orlandi. In: ORLANDI, E. (Org), Discurso Fundador. Campinas, SP: Pontes.

LEVI-STRAUSS, C. (1964). Mythologiques. Paris: Plon.

ORLANDI, E. P. (1983). A Linguagem e seu Funcionamento - as formas do discurso. São Paulo: Brasiliense.

. (1996). Interpretação. Campinas, SP: Vozes.

PÊCHEUX, M. (1969). Analyse automatique du discours. Paris: Dunod.

Pontes Editores.

(2019). Análise Automática do Discurso. Campinas, SP: - (1975). Les Vérités de la Palice. Paris: Maspero.

- (1988). Semântica e Discurso: uma crítica à afirmação do óbvio. Campinas, SP: Editora da Unicamp. . et alii (1981). Matérialités Discursives. Lille: PUL. Unicamp.

. (2016). Materialidades Discursivas. Campinas, SP: Editora da

- (1990). Discurso: estrutura ou acontecimento? Campinas: Pontes.

UlMANN, F. (1952). Précis de Sémantique Française, Berna: A. Francke. 
Palavras-chave: Análise de Discurso, linguagem e exterioridade, efeito-sujeito, efeitos de sentidos, ideologia.

Mots-clés : Analyse du discours, langage et extériorité, effet-sujet, effets de sens, idéologie.

\section{Notas}

* Doutora em Linguística pela Universidade de São Paulo (USP) e pela Universidade de Paris/Vincennes (1976). É pesquisadora-fundadora do Laboratório de Estudos Urbanos (Labeurb) da Universidade Estadual de Campinas (UNICAMP) e docente colaboradora do Departamento de Linguística do Instituto de Estudos da Linguagem (IEL) da UNICAMP. É pesquisadora 1A do CNPq.

${ }^{1}$ Paris, Dunod, 1969.

${ }^{2}$ Entre eles, não só os que faziam parte da sua equipe, mas, também, outros, como M. Culioli e J.J. Milner.

${ }^{3}$ Garantindo a especificidade de cada área, são quatro os pontos relacionados ao processo de modelização: o método de raciocínio; o objeto de representação; as relações entre os objetos; as formas de representação gráfica.

${ }^{4}$ Quanto à Análise de Discurso, a dificuldade com que se confrontava mais frequentemente era a de formalizar questões relativas ao sujeito, mas também ao político e ao estatuto do simbólico.

${ }^{5}$ Vista por este ângulo, o gerativismo ou teoria gerativa é a busca de formalização dos fatos linguísticos aplicando-se um tratamento matemático preciso, explícito e finito às propriedades das línguas naturais. A figura mais representativa é a de Noam Chomsky. A gramática é um sistema de regras e de princípios, formalizado ou explícito, automaticamente aplicado desde que satisfeitas as condições necessárias, podendo criar infinitas frases. Este é considerado o aspecto de "criatividade" deste modelo. Para isto distingue competência e performance: competência é a capacidade que todo sujeito (sujeito ideal) tem de produzir e compreender infinitas frases da língua; a performance é o desempenho, ou seja, a realização da competência. Vamos voltar a esta questão no corpo deste texto.

${ }^{6}$ Ele gostava de "máquinas" e era um visionário.

${ }^{7}$ Mas há diferentes trabalhos que têm sido feitos, mesmo mais recentemente, como o PLN, que assim se apresenta: "neste trabalho, busca-se fornecer uma breve apresentação do domínio de pesquisa multidisciplinar denominado Processamento Automático de Línguas Naturais (PLN), que visa a capacitar um computador para lidar com a língua. Por meio dessa apresentação, traça-se uma determinada concepção de PLN, segundo a qual essa área é uma espécie de "engenharia do conhecimento linguístico". Dessa forma, o PLN requer a descrição e formalização de dados linguísticos nas dimensões morfológica, sintática, semântico-conceitual e até mesmo pragmático-discursiva. Tratamento computacional da língua" (FELIPPO e DIAS-DASILVA, 2009).

Líng. e Instrum. Linguíst., Campinas, SP, n. 44, p. 138-156, jul./dez. 2019 
${ }^{8}$ Eu mesma fiz o curso de "Quadros formais da matemática aplicados à análise da linguagem", ministrado por Y. Gentilhomme, nos anos 70 do século XX, uma disciplina do curso de linguística, no IFCH, da Unicamp, onde estava a Linguística.

${ }^{9}$ Vale observar que, em meus trabalhos, não tomo o texto como unidade linguística, mas discursiva, como unidade de sentido em relação à situação, isto é, em relação às condições de produção. Daí a possibilidade de tomá-lo como unidade de análise. E chego à prática de análise efetiva, ao levar em conta o "conjunto de discursos possíveis", com a noção que desenvolvo de "versões".

${ }^{10}$ E penso que ainda não está feita. Lembro aqui a afirmação de P. Henry ("Sujeito, sentido, origem") de que a questão semântica é uma questão aberta porque é uma questão filosófica; e também L. Hjelmslev para quem a questão semântica é uma questão antropológica.

11 Não seria preciso, mas não custa acentuar, aqui, que a noção de "condições de produção", presente em todos os recortes que fiz do texto da AAD69, sustenta-se como noção fundadora da Análise de Discurso, ligada à noção de "processo de produção" do discurso. A tentativa de evitar estas noções é a de não se vincular ao materialismo histórico.

12 Penso que, neste caso, a Semântica Discursiva se realiza com a Análise de Discurso proposta por ele e desenvolvida por diferentes modelos de análise, como se desenvolveu no Brasil. Tomo, como exemplo, os trabalhos analíticos em que se dá consequência à definição da Teoria do Discurso como determinação histórica dos processos de significação, e, metodologicamente, com a produção de procedimentos analíticos a partir da distinção do dispositivo teórico e dispositivo analítico da interpretação, que faço (ORLANDI, 1996), e o trabalho de análise com a noção de formação discursiva e interdiscurso.

13 Veja-se que já fazemos um deslocamento: não perguntamos se a Análise de Discurso é possível, pois já a praticamos desde os anos 70 do século XX, tendo produzido desenvolvimentos importantes, sobretudo no Brasil. O que nos fica é a questão se a Semântica Discursiva é modelizável, tal como a Semântica Linguística seria.

${ }^{14}$ Não estamos, aqui, ignorando a possibilidade de a análise de discurso trabalhar com outras linguagens que não a verbal. Tomamos apenas o que diz Pêcheux quando fala da questão da análise face ao discurso. Neste caso, ele toma a língua como material de base face aos processos discursivos. Condição de desenvolvimento das discursividades.

${ }^{15}$ Pelo menos nesta época.

${ }^{16}$ Do mesmo modo, com a noção de interdiscurso, são elencados procedimentos para se considerar, na análise, a questão da repetição e do deslocamento.

${ }^{17}$ Lembremos que outra ruptura também é objeto da proposta feita por Pêcheux, no caso das Ciências Humanas e Sociais: a da continuidade existente entre a ideologia e as ciências constituídas nesta região.

${ }^{18}$ Em uma passagem do Vérités de la Palice (1975) - traduzido e publicado no Brasil como "Semântica e Discurso: uma crítica à afirmação do óbvio", em 1988 - Pêcheux diz que a fala "não é o conceito de um elemento contraditório dialeticamente ligado ao conceito de língua, mas um tipo de anti-conceito, um puro excipiente ideológico 
que vem "completar", por sua evidência, o conceito de língua, logo um tapa-buraco, um remendo que oculta a "lacuna" aberta pela definição científica de língua como sistematicidade em funcionamento", e que, como ele diz, é um "excipiente ideológico" (PÊCHEUX, 1988 [1975], p. 245), que sutura. Para sair desta armadilha teórica, o autor mobiliza a noção de "exterioridade" (condições de produção, que, como a penso, inclui sujeito, situação e memória discursiva) e a de ideologia. Ao fazer esta crítica à noção de fala, M. Pêcheux não atribui um "erro" a Saussure, mas como ele diz, "sua falha constitutiva, o lugar central em que o pensamento saussuriano transborda e é recoberto pelo impensado, de que tinha se separado" (PÊCHEUX, 1988 [1975], p. 245). Esta é uma contradição de que vive a Linguística desde Saussure, entre a existência e o uso da língua.

${ }^{19}$ Distinta do que é em M. Foucault.

${ }^{20} \mathrm{Ou}$ outra teoria qualquer.

${ }^{21} \mathrm{O}$ meu interesse pela polissemia me levou a receber muitas críticas dos linguistas que me diziam que esta não era uma questão linguística, mas da literatura.

${ }^{22}$ Vou propor mais tarde a noção de texto, redefinida, como unidade de análise em relação à situação. Não é, em minha definição, nem uma unidade "linguística", nem é fechada.

${ }^{23}$ Resta acrescentar que, a partir da crítica à Linguística saussuriana (oposição língua/fala; sociedade/indivíduo) desenvolvi a proposta de uma teoria do sujeito em que trago para a análise a relação entre a forma-sujeito histórica (de Pêcheux) e o que chamo de processo de individuação do sujeito pelo Estado (instituições e discursos), que resulta na constituição do indivíduo sócio-político, distinto do indivíduo biopsíquico, que, segundo Pêcheux (1975), precederia a interpelação do indivíduo em sujeito. Com isto pude ir além da oposição indivíduo-sociedade, trazendo a simbolização do político para a constituição mesma do sujeito individuado pelo Estado, uma vez constituída a forma-histórica sujeito pela interpelação ideológica.

${ }^{24}$ Estes meus adquiridos, mais a leitura exaustiva de análises de discurso que ia encontrando em diferentes bibliografias, me preparavam para praticar o método e os procedimentos analíticos face a teoria do discurso e a caracterização já feita de seu objeto: o discurso. Com estes elementos, dei muitas aulas e orientei muitos mestrandos e mesmo doutorandos, que iam aprendendo, na relação com os materiais que escolhiam para a análise, que tinham de enfrentar o ineditismo de seu objeto de análise e encontrar procedimentos adequados, relacionando teoria e análise o tempo todo. E assim foi se constituindo, a partir de minhas aulas e orientações, um conjunto de analistas de discurso em sua práxis analítica. Que se desenvolveram e se tornaram independentes em suas propostas de análise a partir desta práxis. A pergunta recorrente, quando chegavam a mim era: tem alguma análise já feita que pode me servir de base? E a resposta era, invariavelmente: não; você tem de ler muita teoria, considerar os conceitos fundamentais para sua análise e encontrar procedimentos analíticos que se inscrevam no método de análise de discurso. Noções como formação discursiva, interdiscurso, recorte, etc, orientavam no estabelecimento do método de análise. A partir de certo momento desenvolvi a relação entre dispositivo analítico e dispositivo teórico da interpretação, o que tornou mais explícitos certos procedimentos de análise e mais posto o método.

Líng. e Instrum. Linguíst., Campinas, SP, n. 44, p. 138-156, jul./dez. 2019 
25 Posso dizer que, ao contrário, eu temia o excesso de modelização e os magros resultados obtidos na Linguística. Onde ficavam os sujeitos e o mundo, se não fosse in vitro?

${ }^{26}$ Insisto em afirmar como foi importante, na minha formação, a noção de estrutura, que me ensinou a passar ao largo do "conteudismo" ou da separação entre forma e conteúdo, quando elaborei, impulsionada pela análise de discurso, outros sentidos para a noção de "forma material" (presente em L. Hjemslev). 